\title{
Neurofibromas as bilateral cystic chest wall swellings.
}

\author{
Ugare, Gabriel ${ }^{1}$, Joshua Omotosho², Anietefon Aetiuma², Okon Bassey²
}

1. Ugare Gabriel, Calabar, Surgery; university teaching hospital,calabar, surgery

2. Omotosho Joshua teaching hospital, Calabar

\begin{abstract}
A 35 year old male farmer presented with soft bilateral posterior chest wall swellings. He had no similar swellings elsewhere. There were no associated symptoms, except cosmetic deformity and discomfort when he lies on his back. A clinical diagnosis of posterior chest wall lipomata was made. However at surgery, the two tumours were completely cystic. Following total excision, histology of the two tumours revealed cystic degeneration of neurofibromas. His postoperative recovery was uneventful. The importance of this report is to emphasize the need for histological examinination of all excised human tissues, which is not always the case in most of our rural areas and to document the discovery of such a rare clinical entity in our centre. This rare entity should be borne in mind when considering the differential diagnosis of benign cystic chest wall tumours.
\end{abstract}

Key words: neurofibromatosis, cystic swelling, posterior, chest, wall.

DOI: http://dx.doi.org/10.4314/ahs.v14i3.40

\section{Introduction}

The chest, both its wall and cavity is an important segment of the body. This is because of the complexity of its wall layers, and the critical functions of the organs contained in its cavity both of which are directly related to life. Chest wall tumours may be primary or secondary; $[1,2]$ and may be benign or malignant. Primary tumours originate denovo from the layers of the chest wall, while metastases from elsewhere are refer to as secondary tumours [.3-5]

Some of these chest wall tumours (swellings), may arise secondary to an infection, usually parasitic infections [6,7]. However, cystic tumours of the chest wall resulting from degenerative changes in peripheral nerves of its layers are rare, and we did not see any in the published literature. We are reporting a single case of bilateral cystic degenerative changes in neurofibromas that presented clinically like chest wall lipomata in a 35 year old male adult.

\section{Case Report}

A 35 year old male farmer presented in our clinic with a 7 month history of bilateral posterior chest wall swellings. The right swelling was noticed a few days after the left. Both were not tender and not associated with neither local nor systemic symptoms; except cosmetic deformity. No past history of trauma to the area, and no family history of neurofibromatosis. He had received traditional[application of herbs] and orthodox treatment[antibiotics ] from traditional healers, chemist and private clinics to no avail. He did not smoke cigarette nor take alcohol, and had no history of drug allergy.
On examination, his vital signs were all within normal ranges. The essential findings were in the posterior chest wall, distal to the inferior scapula angles; where two swellings, measuring approximately $24 \times 18 \times 6 \mathrm{~cm}$ and $23.5 \times 15 \times 6$ located below the inferior angles of the scapulae (figure 1), firm to touch non tender, not warm, lobulated when tensed, and lying subcutaneously. There were no changes in the surrounding hair distribution, skin texture and no palpable auxiliary nodes. No other nodules or café- lait spots elsewhere .Chest auscultation was satisfactory. A working diagnosis of posterior chest wall subcutaneous lipomata was made, with dermoid cysts as a differential.

Investigations done and their results are as follow : urinalysis, normal; a full blood count(complete blood count): total white cell count was $4.7 \times 109 / \mathrm{L}$ (neutropils 30\%, lymphocytes $64 \%$, and eosinophils $6 \%$ ), haemoglobin $10 \mathrm{~g} / \mathrm{dl}$ and ESR of $130 \mathrm{~mm} / \mathrm{hr}$ (westergen).Chest radiographs showed bilateral soft issue shadows on the posterior chest wall. Magnetic resonance imaging (MRI) and computerized tomography (CT) scan were not done as they are not available in our centre.

The masses were excised electively one week later. Findings at surgery were: Two well capsulated tensed cysts of approximately $15 \times 10 \times 5 \mathrm{~cm}$, (figure 2) containing dark brown fluid. The surrounding tissues were normal, with no evidence of necrosis or hemorrhage. Samples were sent for histopathology and the result revealed cystic masses with irregular wall thickening. Their cavities measure about $9 \mathrm{~cm}$ in the widest diameter. The turmour cells were elongated spindle shaped type with basophilic serpenture nuclei, and with marked perivas- 
cular lymphatic infiltration (figure 3). A histopathologic diagnosis of neurofibromas with cystic degeneration was made.

The postoperative period was uneventful (figure 4), and the patient was discharged from the ward on the 10 the postoperative day. His condition has been stable, with no evidence of recurrence, one year after.

\section{Discussion}

Cystic tumours of the chest wall have been documented in medical literature worldwide and they may be congenital [ 8] or acquired [9] in origin. Most acquired cystic chest wall tumours are secondary to helminthic infections, often by echinococeal worms seen in sheep breeding areas such as in the Middle East.

Congenital cystic tumours occur commonly in paediatric age group [3], cystic tumours in adults may arise from tissues of the chest wall; and may be dermal, lympho-vascular, or bony in origin $[3,5,8]$.

Cystic chest wall tumours in our environment are rare, as the study from Benin City reveals [1]: in the six years 1995 - 2001, Ofoegbu and colleague saw seven solid chest wall tumours, all in adults' age 22 to 56 years. Fifty seven percent were soft tissue tumours, others from bone and cartilage. No cystic tumour was recorded in their report. From our literature search, cystic chest wall tumours in adults are usually acquired, and often secondary to helminthic infestations $[6,7,9]$.

Tumours that may arise denovo from the chest wall tissues in adults are often from the bone, nerves, cartilage or chest wall soft tissues, and are usually solid tumours $[4,8,9]$. A tumour may also arise secondary to trauma [9]. We did not find in current medical literature cystic tumours of the chest wall tissues in adult arising denovo, nor secondary to degenerative changes in peripheral nerve tumours nor other tumour types; thus we are reporting a completely new clinical disease entity.We think that the cystic nature is due to degenerative changes in what was probably a solid lesion, either spontaneously or secondary to trauma.The bilaterality is explained by the fact it arises from corresponding nerve roots most likely $\mathrm{T} 6 / 7$ in view of its location.

Chest wall tumours usually present as chest wall swellings, often painless with no systemic symptoms. Essential imaging investigations include chest radiographs and computerized tomography scan or MRI [Magnetic Resonance Imaging] are necessary for adequate assessment of the patient, and to plan appropriate treatment $[3,5]$. Surgical excision is the rule and in large tumours where significant chest wall defect may occur following excision, thoracoplasty is done, either immediately or later to close the defect $[6,7]$.

In our index patient, simple surgical excision with skin apposition was adequate, with uneventful recovery. This modality of treatment may have averted the possibility of rupture and malignant transformation of the lesion. He has remained in good health with no recurrence 2years after, when contacted by mobile phone.

\section{Conclusion:}

We conclude that these were primary cystic tumours in an adult patient probably from sequestered nerve tissues during embryogenesis. Their rapid growth may be explained by the cystic and haemorrhagic changes (as indicated by their content). This is a rare and yet to reported clinical phenomenon in our centre. We also advice that cystic chest swellings even though may be of infective origin are better managed surgically, with a proper histology of excised tissues. The reasons are that; even a cystic helminthic infestation may not be completely cured with antihelmintics, and a primary or secondary malignancy may undergo cystic degeneration. We also wish to point the role that mobile phones may play in clinical practice in Sub-Saharan Africa, where poor patients often live far from the health institution.

\section{References:}

1. Reginald OO, Aligbe JU. Primary Tumours of the chest wall. Nig. J Surg. Sc. 2001; 11: 43 - 6.

2. Steltzer P, Gay WA. Tumours of the chest wall. Surg. Clf North Am. 1989; 60: 779 -91.

3. Kocher HM, Vijaykumar T, Koti R S. Bapat RD. Lymphangioma of the Chest wall. J Postgrad. Med. 1995; 41: $89-90$.

4. Michael P, Filis C, Pikoulis E, Varelas P, Mihail S, Bastounis E. Chest wall ectopic synovial bursa cyst. South Afri.Med.l J 1999; 92: 1108 -9.

5. Saoji R, Heroor A.. Sharma. S, Deshpande R. Aneurysmal bone cyst of the chest wall. Eur. J. Cardiothorc. Surg. 2001; 20: 1030.

6. Karapinar K, Altinok D, Cetingok U, Duzgun C. Primary Posterior chest wall echinococcosis. Inter. Surg. 1999; $84: 89-90$.

7. Shalabi RI, Ayed AK, Anim M. Fifteen years in Surgical Management Pulmonary hydratidosis. Ann Thorac. Cardiovasc Surg. 2002; 8):131- 4

8. Serrano-Egea A, Santo-Briz A, Garcia-Munoz H, Martinez-Tello F.J. Chest wall harmatoma:a report of two cases with secondary aneurismal bone cysts. Path. Resec. Pract. 2001; 197: 835-9.

9. Ballas K, Rafailidis S, Simeonidis N, Papanikolaou K, Aimoniotou E, Sakadamis AK. Anterior chest wall 
tramatic lymphocele: A case report. Acta. Chir. Belg. 2007; 107: 78 - 80 .
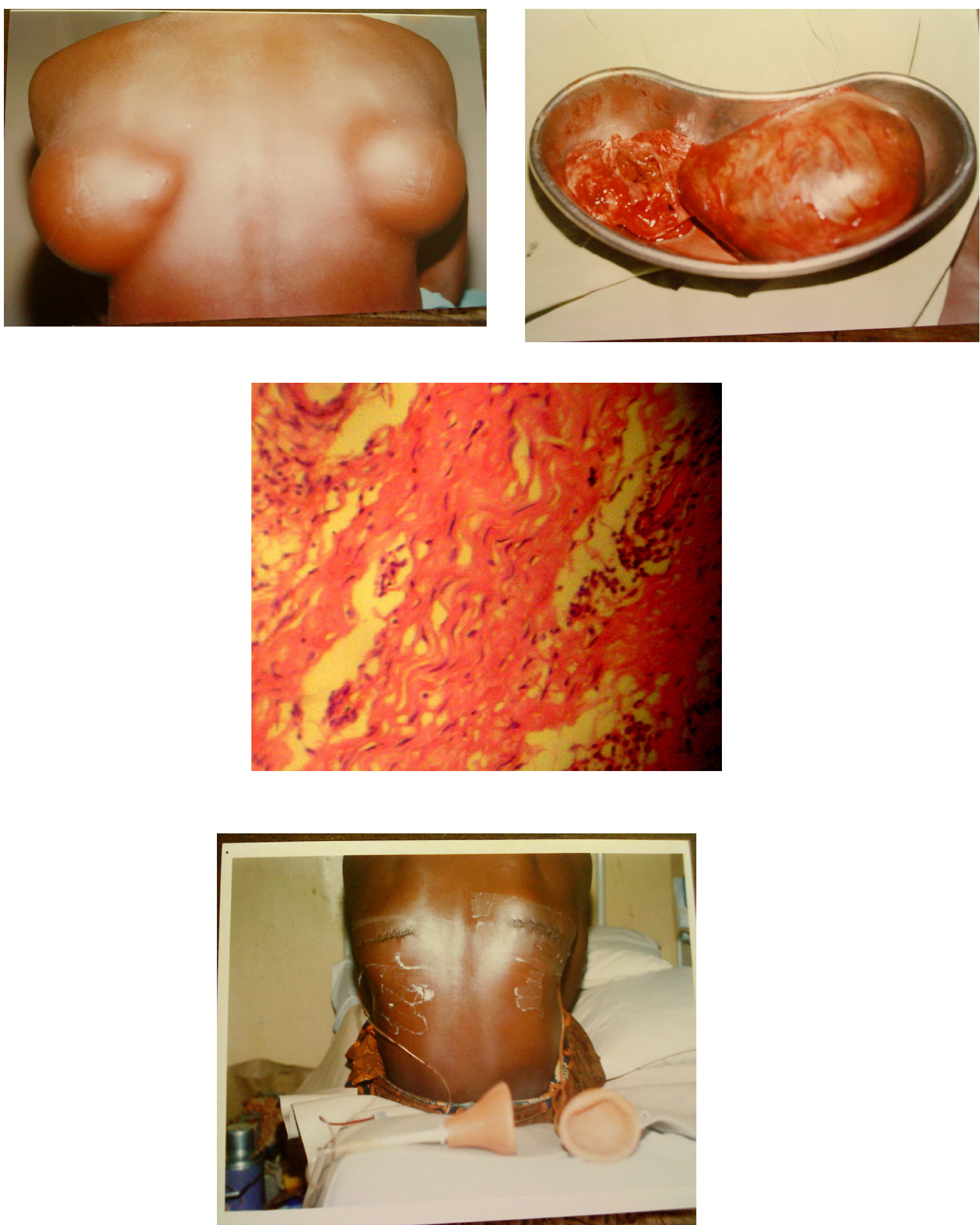